\title{
Predictors of adverse perinatal outcomes in intrahepatic cholestasis of pregnancy
}

\author{
Samettin Çelikk ${ }^{1}$ Canan S. Çalışkan ${ }^{1}$, Handan Çelik² , Mehmet Güçlü ${ }^{3}$, Alper Başbuğ ${ }^{4}$ \\ 'Obstetrics and Gynecology, Samsun Research and Education Hospital, Turkey \\ ${ }^{2}$ Ondokuz Mayıs University, Department of Obstetrics and Gynecology, Turkey \\ ${ }^{3}$ Pendik Training and Research Hospital, Department of Obstetrics and Gynecology, Turkey \\ ${ }^{4}$ Düzce University, Department of Obstetrics and Gynecology, Turkey
}

\begin{abstract}
Objectives: Our objective was to evaluate in our clinic the perinatal outcomes of patients diagnosed with ICP based on pre-treatment maternal serum bile acid levels, attempt to identify the risk group and review the literature in light of this information.

Material and methods: In total, 370 patients diagnosed with ICP were included in the study, divided into two groups based on the fasting total serum bile acid level before UDCA (Group 1: $10 \geq 40 \mu \mathrm{mol} / \mathrm{L}$, and Group 2: $\geq 40 \mu \mathrm{mol} / \mathrm{L}$ ). The groups were examined for clinical characteristics and pregnancy outcomes.

Results: It was found that preterm delivery and neonatal intensive care need increased at a serum bile acid cut-off value of $34 \mu \mathrm{mol} / \mathrm{L}$. Regardless of serum bile acid, significantly higher rates of meconium-stained amniotic fluid and foetal distress were observed in patients whose diagnoses were made before 34 weeks of gestation.

Conclusions: Foetal complications over $40 \mu \mathrm{mol} / \mathrm{L}$ of serum bile acid were significantly increased. However, slightly lower levels cut-off values $(34 \mu \mathrm{mol} / \mathrm{L}$ ) were obtained in terms of preterm birth and neonatal intensive care need. The incidence of meconium-stained amniotic fluid and foetal distress was higher in patients whose diagnosis were made before 34 weeks of gestation.
\end{abstract}

Key words: intrahepatic cholestasis; pregnancy; perinatal complications

\section{INTRODUCTION}

Intrahepatic cholestasis of pregnancy (ICP) is a pregnancyspecific liver disease. ICP, which is frequently seen in the second or third trimester, is also the most common liver disease in pregnancy. Maternal pruritus and elevated serum bile acid and/or transaminase levels are characteristic findings. ICP prevalence varies between regions and races. The incidence of the disease is reported to be $0.1 \%$ to $15.6 \%$ world wide [1]. The maternal effects of ICP have a benign course, although ICP can lead to important consequences in the foetus and can cause many foetal complications, including intrauterine foetal loss [2]. Human and animal studies have shown that the transplacental transfer of bile acids is impaired in ICP patients $[3,4]$.

To avoid foetal complications caused by ICP, delivery either after foetal lung maturation or 37 weeks is a frequently used approach [4, 5]. It is thought that markedly elevated bile acids and advanced gestation are more important in the development of foetal complications [2]. As a result, there are data showing that the same approach should not be used in every ICP patient; in particular, a more expedient approach should be taken for patients with serum bile acids below $40 \mu \mathrm{mol} / \mathrm{L}$, although this issue is still unclear.

\section{Objectives}

The objective of this study was to examine the fasting serum bile acid levels of ICP patients between specific ranges and to evaluate foetal complications in patients diagnosed with ICP, examining perinatal outcomes in these patient groups. Since ICP patients with maternal total serum bile acids $<40 \mu \mathrm{mol} / \mathrm{L}$ are considered to be at low risk in the literature, we evaluated patients in two groups according 
to serum bile acid level $40 \mu \mathrm{mol} / \mathrm{L}$. We also reviewed foetal outcomes in ICP patients before or after 34 weeks gestation.

\section{MATERIAL AND METHODS}

There were 21,000 pregnant women who gave birth at Samsun Training and Research Hospital between 20122018 and who were followed-up. Overall, 436 of these patients was diagnosed with ICP.The incidence of cholestasis of pregnancy in our hospital was found to be $2 \%$. Of these patients with ICP, 370 were included in the study. Patients free from any liver disease or skin pathology who had persistent pruritus without primary skin lesions, elevated fasting total serum bile acid ( $\geq 10 \mu \mathrm{mol} / \mathrm{L}$ ) and/or liver enzymes were diagnosed with ICP. Sixty-six patients diagnosed with ICP were not included in the study. Patients who had multiple pregnancies and patients with congenital or chromosomal anomalies were not included in the study. Likewise, patients who were diagnosed with chronic liver disease and viral infection (hepatitis $A, B, C$ infections) were excluded from the study. Ursodeoxycholic acid (UDCA) was started (250 mg three times a day) in patients diagnosed with ICP. Based on the patient's symptoms, UDCA dosage was increased after 1-2 weeks (maximum $2000 \mathrm{mg} /$ day) if needed. The gestational week of the patients was calculated according to the reliable last menstrual period and/or ultrasonographic measurements in the early gestational period. Patients were followed up with biophysical profile 1-2 times per week based on their respective gestational week.

Blood was collected for the determination of fasting total serum bile acid in patients who presented to the hospital with pruritus without primary skin lesions. Maternal fasting total serum bile acids were sent to the Düzen Laboratory in Ankara as a reference centre. The patients did not receive UDCA before the biliary acid results came back and ICP diagnosis was made. Other laboratory tests were performed in the biochemistry department of our hospital. If gestational week was appropriate for follow-up, maternal fasting serum bile acids were reworked one week after UDCA was started and weekly serum biochemical tests were performed.

Patients who were diagnosed with ICP and who were included in the study were divided into two groups (Group 1: $10-40 \mu \mathrm{mol} / \mathrm{L}$, and Group 2: $\geq 40 \mu \mathrm{mol} / \mathrm{L}$ ) based on the fasting total serum bile acid level before UDCA was initiated. Maternal demographics, medical comorbidities, and serum biochemical parameters were obtained from the hospital database. Delivery induction was achieved with intravenous oxytocin infusion following cervical ripening with $10 \mathrm{mg}$ prostaglandin E2.

Perinatal outcomes of ICP patients included in the study were evaluated by the groups divided based on the serum bile acid levels. The gestational week at diagnosis, week of delivery, route of delivery, birth weight, intrauterine growth retardation (IUGR), foetal distress, stillbirth, the need for intensive care (NICU) and intubation of the baby, meconiumstained amniotic fluid, and five minute Apgar score were recorded. The Apgar score includes newborn breathing, heartbeat, muscle tone, laryngeal reflex and skin colour; Apgar scores $\leq 7$ were considered to be low. Delivery before 37 weeks of gestation was considered preterm birth. If foetal weight was less than $10 \%$ per centile based on the gestational week, IUGR was accepted. Patients with severe cholestasis of pregnancy were delivered between 34-37 weeks considering maternal complications and foetal condition, and a delivery was planned immediately for patients whose diagnosis was made at or after 38 weeks of gestation. In patients with mild cholestasis, delivery was planned at 37-38 weeks.

\section{Statistical analysis}

The descriptive statistics for continuous variables were expressed in mean \pm standard deviation or median (minimum-maximum), while nominal variables were expressed as the number and percentage (\%). The significance of the difference between the mean values of the groups was evaluated using the Student's t-test, while the significance of the difference in the median values was evaluated using the Mann-Whitney $U$ test. Categorical data were compared by Chi-square distribution. Univariate Binary Logistic Regression analysis was used to analyse the effect of the cholestasis of pregnancy on perinatal outcomes. A p value of $<0.05$ was considered statistically significant. Statistical analysis was performed using SPSS for Windows version 22 software (SPSS Inc., Chicago, IL, USA).

\section{RESULTS}

In total, 21,000 deliveries took place in our hospital between 2013 and 2018. Of these patients, 436 experienced cholestasis of pregnancy, and 58 were multiple pregnancies. The study included 370 patients with cholestasis of pregnancy who were singleton pregnancies.

The demographics and laboratory characteristics of the patients are presented in Table 1. The mean age of the patients was $27.7 \pm 5.3$ (range 18-42) with $56 \%$ nulliparous and $44 \%$ multiparous. Mean gestational week at diagnosis was $33.1 \pm 2.8$ (range 27-39). The mean gestational week at delivery was $36.5 \pm 1.2$ (range $32-39$ ). A total of 83 patients (22.4\%) gave birth before 37 weeks and 20 of these patients (5.4\%) gave birth before 34 weeks.

The indication for the induction of labour was cholestasis of pregnancy in most patients. There was no intrauterine foetal demise in any of the patients. The incidence of preeclampsia and gestational diabetes mellitus was $4.9 \%$ and $6.9 \%$, respectively.

Patients were divided into two groups based on the fasting serum bile acid level at diagnosis. In the first group, 


\begin{tabular}{|c|c|}
\hline n & 370 \\
\hline Age [years] (mean \pm SD) & $27.7 \pm 5.3$ \\
\hline Gravidity [range] & $1-7$ \\
\hline $\begin{array}{l}\text { Gestational age at diagnosis [weeks] } \\
\text { (mean } \pm \text { SD) }\end{array}$ & $33.1 \pm 2.8$ \\
\hline Gestational Diabetes [\%] & 6.9 \\
\hline Preeclampsia [\%] & 4.9 \\
\hline Intrauterine growth retardation [\%] & 5.1 \\
\hline $\begin{array}{l}\text { Gestational age at delivery [weeks] } \\
\text { (mean } \pm \text { SD) }\end{array}$ & $36.5 \pm 1.2$ \\
\hline Delivery < 37 weeks of gestation [n] & 83 \\
\hline Delivery $<34$ weeks of gestations [n] & 20 \\
\hline \multicolumn{2}{|l|}{ Delivery methods (\%9 } \\
\hline Vaginal & $42 \%$ \\
\hline Caesarean section & $58 \%$ \\
\hline $\begin{array}{l}\text { Total bile acid at diagnosis / after } \\
\text { treatment }[\mu \mathrm{mol} / \mathrm{L}](\text { mean } \pm \mathrm{SD})\end{array}$ & $46.0 \pm 41.67 / 20 \pm 6.8$ \\
\hline $\begin{array}{l}\text { ALT at diagnosis / after treatment } \\
{[U / L](\text { mean } \pm \text { SD) }}\end{array}$ & $85.1 \pm 69.6 / 33.3 \pm 28.9$ \\
\hline $\begin{array}{l}\text { AST at diagnosis /after treatment } \\
{[\mathrm{U} / \mathrm{L}](\text { mean } \pm \text { SD) }}\end{array}$ & $79.9 \pm 55.7 / 32.2 \pm 27.1$ \\
\hline $\begin{array}{l}\text { Total bilirubin at diagnosis / after } \\
\text { treatment }[\mu \mathrm{mol} / \mathrm{L}](\text { mean } \pm S D)\end{array}$ & $1.5 \pm 4.8 / 1.3 \pm 0.7$ \\
\hline $\begin{array}{l}\text { ALP at diagnosis / after treatment } \\
{[\mu \mathrm{mol} / \mathrm{L}](\mathrm{mean} \pm \mathrm{SD})}\end{array}$ & $246.8 \pm 131.7 / 203.0 \pm 103.1$ \\
\hline
\end{tabular}

serum bile acid levels were $<40 \mu \mathrm{mol} / \mathrm{L}$ (mild cholestasis, 246 patients), while they were $\geq 40 \mu \mathrm{mol} / \mathrm{L}$ (severe cholestasis, 124 patients) in the second group. The demographics and clinical data of both groups are presented in Table 2 .

The gestational week at presentation was 35 weeks (range 29-39) in the mild cholestasis group and 32 weeks (range 27-36) in the severe cholestasis group ( $<<0.001)$.

The gestational week at diagnosis was statistically significantly earlier in patients with serum bile acid $\geq 40 \mu \mathrm{mol} / \mathrm{L}$. ALT, AST, ALP and total bilirubin levels were significantly higher in the severe cholestasis group versus mild cholestasis group $(p<0.001)$. Similarly, the decrease in serum bile acid, ALT, AST, ALP and total bilirubin levels was faster in the mild cholestasis group versus severe cholestasis group one week after the treatment $(p<0.001)$.

When compared, there was also a significant difference in the incidence of cholestasis in the previous pregnancy between the two groups. The prevalence of cholestasis in a previous pregnancy in the mild cholestasis group was $12.2 \%$ (30 patients), while it was $39.5 \%$ (49 patients) in the severe cholestasis group ( $p<0.001$ ) (Tab. 2).

Table 3 compares the delivery data and perinatal outcomes of the patients based on the groups. Women with severe cholestasis of pregnancy were delivered earlier
Table 2. Demographic and laboratory findings of severe and mild cholestasis

\begin{tabular}{|c|c|c|c|}
\hline Mild Cholestasis $(n=246$ ) & $\begin{array}{l}\text { Severe } \\
\text { Cholestasis } \\
(n=124)\end{array}$ & $p$ value & \\
\hline Age [years] & $27.7 \pm 5.2$ & $27.6 \pm 5.4$ & 0.937 \\
\hline Gravidity & $1(1-6)$ & $1(1-7)$ & 0.446 \\
\hline Parity & $0(0-9)$ & $0(0-5)$ & 0.456 \\
\hline $\mathrm{BMI}\left(\mathrm{kg} / \mathrm{m}^{2}\right)$ & $32.2 \pm 5.2$ & $33.0 \pm 6.1$ & 0.375 \\
\hline $\begin{array}{l}\text { Total bile acids at diagnosis } \\
{[\mu \mathrm{mol} / \mathrm{L}]}\end{array}$ & $25.1 \pm 8.0$ & $87.7 \pm 19.5$ & $0.001^{*}$ \\
\hline $\begin{array}{l}\text { Gestational age at diagnosis } \\
\text { [weeks] }\end{array}$ & $35(29-39)$ & $32(27-36)$ & $0.001^{*}$ \\
\hline AST at diagnosis [U/L] & $62.1 \pm 34.1$ & $115.1 \pm 71.5$ & $0.001^{*}$ \\
\hline ALT at diagnosis [U/L] & $62.3 \pm 35.9$ & $130.1 \pm 94.3$ & $0.001^{*}$ \\
\hline $\begin{array}{l}\text { Total bilirubin at diagnosis } \\
{[\mu \mathrm{mol} / \mathrm{L}]}\end{array}$ & $1.1 \pm 0.4$ & $1.8 \pm 0.9$ & $0.001^{*}$ \\
\hline ALP after treatment $[\mathrm{U} / \mathrm{L}]$ & $208.3 \pm 72.8$ & $323.3 \pm 180.7$ & $0.001^{*}$ \\
\hline AST after treatment [U/L] & $22.6 \pm 15.0$ & $51.5 \pm 34.6$ & $0.001^{*}$ \\
\hline ALT after treatment [U/L] & $24.0 \pm 16.5$ & $45.1 \pm 38.0$ & $0.001^{*}$ \\
\hline $\begin{array}{l}\text { Total bilirubin after } \\
\text { treatment }[\mu \mathrm{mol} / \mathrm{L}]\end{array}$ & $1.0 \pm 0.4$ & $1.7 \pm 0.9$ & $0.001^{*}$ \\
\hline ALP after treatment [U/L] & $173.3 \pm 54.5$ & $262.1 \pm 143.7$ & $0.001^{*}$ \\
\hline $\begin{array}{l}\text { Total bile acids after } \\
\text { treatment }[\mu \mathrm{mol} / \mathrm{L}]\end{array}$ & $18.9 \pm 4.8$ & $24.0 \pm 8.8$ & $0.001^{*}$ \\
\hline
\end{tabular}

in their gestation. Similarly, when the birth weight was compared between the two groups, the birth weight of babies in the severe cholestasis group was significantly lower than that of the mild cholestasis group $(p<0.001)$. There was no significant difference between the two groups in terms of route of delivery.

When the perinatal outcomes were compared between the two groups, meconium-stained amniotic fluid was observed in $7.7 \%$ of patients in the mild cholestasis group and $25 \%$ of patients in the severe cholestasis group $(p<0.001)$. Similarly, the rate of foetal distress was significantly higher in the severe cholestasis group ( $p<0.004)$. Five-minute Apgar score, neonatal intensive care need and intubation rate were significantly higher in the severe cholestasis group $(p<0.001$, $p<0.001$ and $p<0.008$, respectively). When the preterm delivery rates were compared between the two groups, the number of deliveries before 37 weeks was $32(13 \%)$ in the mild cholestasis group and 51 (51.1\%) in the severe cholestasis group ( $p<0.001)$. Similarly, when deliveries before 34 weeks were compared, preterm birth rates were significantly higher in the severe cholestasis group $(p<0.001)$ (Tab. 3 ).

According to the ROC curve analysis demonstrating the significance of the pre-treatment bile acid levels in the determination of preterm births and NICU need between the groups, the serum bile acid cut-off value was found to 
Table 3. Perinatal outcomes of severe and mild cholestasis

\begin{tabular}{|c|c|c|c|c|}
\hline & $\begin{array}{l}\text { Mild cholestasis (Total bile } \\
\text { acids }<40 \mu \mathrm{mol} / \mathrm{L} \text { ) } \\
(\mathrm{n}=246)\end{array}$ & $\begin{array}{l}\text { Severe cholestasis (Total } \\
\text { bile acids }>40 \mu \mathrm{mol} / \mathrm{L}) \\
(\mathrm{n}=124)\end{array}$ & Odds Ratio (\%95 confidence) & $p$ values \\
\hline Gestational age at delivery [weeks] & $37(33-39)$ & $36(32-38)$ & & $0.001 *$ \\
\hline Preterm delivery < 37w [n, \%] & $32(13 \%)$ & $51(51.1 \%)$ & $4.67(2.79-7.82)$ & $0.001^{*}$ \\
\hline Preterm delivery < 34w [n, \%] & $6(2.4 \%)$ & $14(11.3 \%)$ & $5.09(1.90-13.60)$ & $0.001^{*}$ \\
\hline Birth weight [g] & $2990(1850-4250)$ & $2490(1670-3550)$ & & $0.001^{*}$ \\
\hline $\begin{array}{l}\text { Mode of delivery } \\
{[\mathrm{n}, \%]} \\
\text { Vaginal } \\
\text { Casarean section }\end{array}$ & $\begin{array}{l}148(60.2 \%) \\
98(39.8 \%)\end{array}$ & $\begin{array}{l}65(52.4 \%) \\
59(47.6 \%)\end{array}$ & $1.37(0.88-2.11)$ & $\begin{array}{l}0.497 \\
0.155\end{array}$ \\
\hline Meconium staining [n, \%] & $19(7.7 \%)$ & $31(25.0 \%)$ & $3.98(2.14-7.40)$ & $0.001^{*}$ \\
\hline Fetal distress [n, \%] & $34(13.8 \%)$ & $32(25.8 \%)$ & $2.16(1.26-3.72)$ & $0.004^{*}$ \\
\hline 5 min Apgar score (mean \pm SD) & $9(5-10)$ & $8(5-10)$ & & $0.001^{*}$ \\
\hline Perinatal mortality [n] & 0 & 0 & & N.A \\
\hline Neonatal unit admission [n, \%] & $38(15.4 \%)$ & $41(33.0 \%)$ & $4.19(2.17-8.10)$ & $0.001^{*}$ \\
\hline Entubation [n, \%] & 22 (8.9\%) & $13(18.5 \%)$ & $2.31(1.23-4.35)$ & $0.008^{*}$ \\
\hline
\end{tabular}

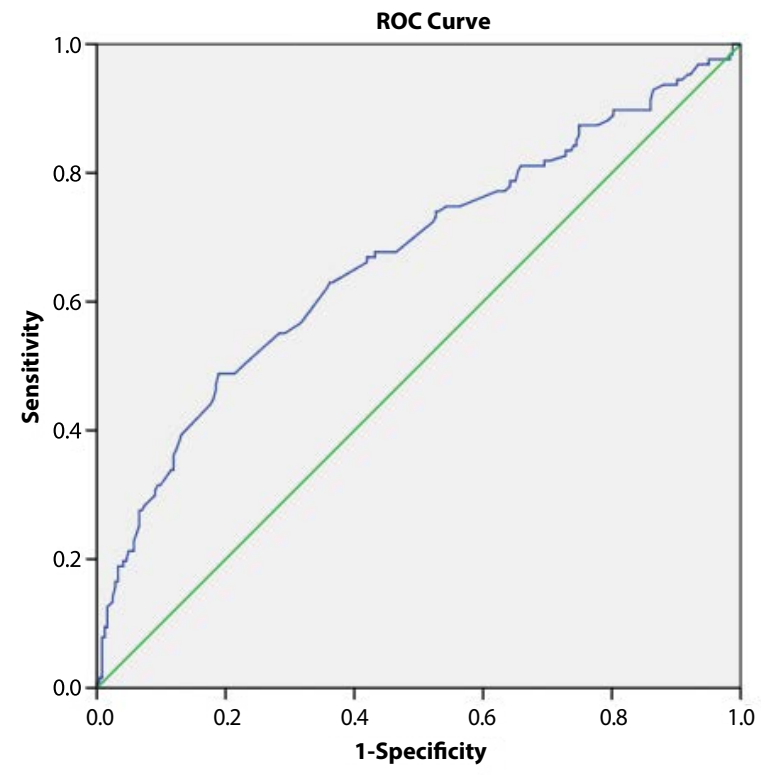

Diagonal segments are produces by ties

Figure 1. ROC curve for the prognostic value of total bile acids at diagnosis and preterm birth

be $34.40 \mu \mathrm{mol} / \mathrm{L}$ and $34.71 \mu \mathrm{mol} / \mathrm{L}$, respectively (for preterm birth Area Under Curve $=0.703, \mathrm{p}=0.001$ (95\% Cl: 0.6440.763) (Fig. 1); for NICU need Area Under Curve $=0.677$, $\mathrm{p}=0.001$ (95\% Cl: 0.584-0.771) (Fig. 2).

When the foetal results were compared based on the gestational week at diagnosis without the evaluation of serum bile acid, significantly higher rates of meconiumstained amniotic fluid and foetal distress were observed in patients whose diagnosis were made before 34 weeks gestation $(p<0.001)$ (Tab. 4).

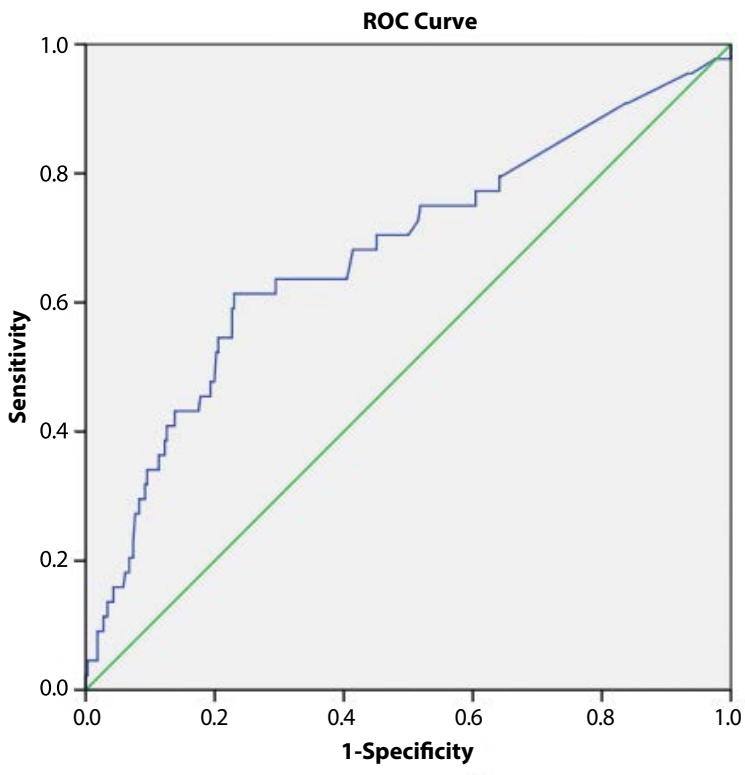

Diagonal segments are produces by ties

Figure 2. ROC curve for the prognostic value of total bile acids at diagnosis and neonatal unit admission

\section{DISCUSSION}

Our study found 3 important points: 1 ) In patients with serum bile acid $\geq 40 \mu \mathrm{mol} / \mathrm{L}$, perinatal complications were significantly increased compared to patients with mild cholestasis; 2) Foetal complications (preterm birth and neonatal intensive care need) are significantly increased at a serum bile acid cut-off value of $34 \mu \mathrm{mol} / \mathrm{L}$, although serum bile acid $\geq 40 \mu \mathrm{mol} / \mathrm{L}$ is a value that is also used in the definition of severe cholestasis in the literature; and 3) Higher rates of meconium-stained amniotic fluid and foetal 


\begin{tabular}{|c|c|c|c|}
\hline & $\begin{array}{l}\geq 34 \text { weeks } \\
(n=20)\end{array}$ & $\begin{array}{l}<34 \text { weeks } \\
(n=350)\end{array}$ & $p$ values \\
\hline $\begin{array}{l}\text { Total bile acids at } \\
\text { diagnosis }(\mu \mathrm{mol} / \mathrm{L})\end{array}$ & $66.73 \pm 11.13$ & $44.97 \pm 22.35$ & 0.023 \\
\hline $\begin{array}{l}\text { Total bile acids after } \\
\text { treatment }(\mu \mathrm{mol} / \mathrm{L})\end{array}$ & $17.79 \pm 14.89$ & $10.15 \pm 7.41$ & 0.001 \\
\hline $\begin{array}{l}\text { Meconium staining } \\
{[\mathrm{n}, \%]}\end{array}$ & $8(40.0 \%)$ & $42(\% 12.0)$ & 0.001 \\
\hline Fetal distress [n, \%] & $9(45.0 \%)$ & $57(\%$ 16.3) & 0.001 \\
\hline $\begin{array}{l}\text { Mode of delivery [n, \%] } \\
\text { Vaginal } \\
\text { Cesarean section }\end{array}$ & $\begin{array}{l}7(35 \%) \\
13(65 \%)\end{array}$ & $\begin{array}{l}206(58.9 \%) \\
144(41.1 \%)\end{array}$ & $\begin{array}{l}0.011 \\
0.036\end{array}$ \\
\hline
\end{tabular}

distress were observed in patients whose ICP diagnosis were made before 34 weeks of gestation compared to the patients whose ICP diagnosis were made after 34 weeks gestation.

Our study has certain strengths. Participants from our single hospital had the same criteria for diagnosis and similar antenatal monitoring of ICP. Bloods from patients obtained to determine the serum bile acid levels were studied in a private reference laboratory at a single centre (Ankara Düzen Laboratory). The study also has several limitations. First, we used a retrospective design, due to the rarity of the disease. Second, although large for studies of intrahepatic cholestasis of pregnancy, our sample size limited our ability to make definitive conclusions about rare foetal complications. Lastly, our study may have errors in that the active management of cholestasis could have resulted in a decreased frequency of adverse foetal outcomes.

The rate of cholestasis of pregnancy in our study was $2 \%$ and the rate of severe ICP was found to be $33 \%$ in all ICP patients. In previous studies, the incidence of cholestasis of pregnancy was $0.7-1.5 \%$ in the UK and severe ICP was observed in $15 \%$ of all ICP patients [6-8]. This ratio was found to be higher in our region.

According to the literature, it seems that ICP patients have an increased risk of preeclampsia and gestational diabetes $[6,7,9]$. Our study also found that the rate of gestational diabetes in ICP patients was higher than in women with normal pregnancies, but there was no difference in preeclampsia.

In our findings, foetal distress and meconium-stained amniotic fluid in ICP patients diagnosed before 34 weeks of gestation were significantly higher than in ICP patients diagnosed after 34 weeks of gestation. We demonstrated that in ICP patients diagnosed before 34 weeks of gestation, the frequency of perinatal complications, especially foetal distress and meconium-stained amniotic fluid, are increased. Estiu et al. also reported an association between meconiumstained amniotic fluid and lower gestational age both at diagnosis and at birth in 382 ICP patients [7]. Similarly, it was stated by Madazlı et al. that foetal complications such as preterm delivery, RDS and IUGR were significantly higher in patients who were diagnosed before 30 weeks than after 34 weeks of gestation [10].

Although ICP is a relatively benign disease for the mother, there are many risks for the babies, including preterm delivery, foetal distress, meconium-stained amniotic fluid, and foetal demise. Glandz et al. concluded that the risk of foetal complications does not occur until serum bile acid levels exceed $40 \mu \mathrm{mol} / \mathrm{L}$ [5]. Since then, other studies have also reported increased foetal complications with serum bile acid levels over $40 \mu \mathrm{mol} / \mathrm{L}$ [11-13]. Cui et al. reported that total bile acid levels $\geq 40 \mu \mathrm{mol} / \mathrm{L}$ are considered to represent severe disease [12]. Although several studies have reported a positive correlation between elevated serum total bile acids and an increased risk of perinatal complications, there are also controversial results [14, 15]. A study by Oztas et al. stated that there is no relationship between serum total bile acid levels and preterm delivery [14]. Madazlı et al. also stated that there was no significant difference between the incidence of RDS, foetal distress and preterm delivery according to serum bile acid levels [10]. In our study, meconium-stained amniotic fluid and foetal distress rates were significantly increased with serum bile acid levels over $40 \mu \mathrm{mol} / \mathrm{L}$. Similarly, neonatal intensive care need and neonatal intubation rates were also significantly increased with serum bile acid levels over $40 \mu \mathrm{mol} / \mathrm{L}$. This study is especially important, as it showed that perinatal complications increase at a lower level of serum bile acid with a cut-off level of $34 \mu \mathrm{mol} / \mathrm{L}$. A cut-off level of $34 \mu \mathrm{mol} / \mathrm{L}$ is first reported in the current study.

One of the major complications of cholestasis of pregnancy is prematurity $[2,16,17]$. In the literature, the incidence of prematurity in ICP patients is 19-60\% [6]. Preterm delivery, which causes prematurity in patients with cholestasis of pregnancy, can be spontaneous and iatrogenic. In vitro studies have shown that serum bile acids, in particular colic acid, increase the expression of oxytocin receptor, and myometrial responses to oxytocin. Spontaneous preterm labour may be explained by a dosedependent bileacid effect on myometrial contractility $[17,18]$. In our study, about half (51\%) of the patients with serum bile acid levels above $40 \mu \mathrm{mol} / \mathrm{L}$ at diagnosis delivered before 37 weeks. Of these patients, $49 \%$ delivered spontaneously and $51 \%$ were iatrogenic premature birth.

In our study, distinct from other studies, the serum bile acid level of $34 \mu \mathrm{mol} / \mathrm{L}$ was determined as the cut-off value for preterm birth. In the literature, a maternal serum bile acid level of $\geq 40 \mu \mathrm{mol} / \mathrm{L}$ was demonstrated as the threshold for foetal complications in most publications. In our study, we also observed an increase in all foetal complications 
over $40 \mu \mathrm{mol} / \mathrm{L}$ (preterm delivery, meconium-stained amniotic fluid, foetal distress, neonatal intensive care need and newborn intubation rates). We also found the serum bile acid level of $34 \mu \mathrm{mol} / \mathrm{L}$ to be the cut-off value for the determination of risk of preterm birth and neonatal intensive care need.

The incidence of stillbirth is 1.5\% in ICP in the literature[11]. The mechanism causing stillbirth in ICP is poorly understood. At autopsy, the babies have no signs of chronic uteroplacental insufficiency, but do have evidence of acute anoxia $[11,18]$. It seems that intrauterine foetal demise risk increases after 37 weeks of gestation, also related to the higher serum level of bile acids in ICP. Examination of the placental changes in ICP patients support the theory of an acute event that can cause foetal demise [4]. The possible mechanisms for acute foetal demise may be cardiac arrhythmia or sudden vasospasm of placental chorionic surface vessels due to bile salts. Further evidence for this hypothesis comes from the studies that cultured neonatal cardiomyocytes show decreased contractility and develop arrhythmogenic activity when exposed to bile acids [19,20]. There were no intrauterine deaths in our study. The reason for this might be that the timing of delivery in ICP patients was planned to be 37-38 weeks at the latest, immediate delivery with labour induction or caesarean section was planned in patients diagnosed with ICP after 38 weeks and later, while patients with severe cholestasis patients with higher bile acid levels were delivered at 34-37 weeks.

\section{CONCLUSIONS}

In conclusion, we found that foetal adverse effects are more frequent when the cholestasis was recognised before 34 weeks of pregnancy or when the serum bile acids are higher than $34 \mu \mathrm{mol} / \mathrm{L}$. Cholestasis of pregnancy is still not a clearly manageable disease and the timing of delivery and prediction of foetal complications are still unclear in the prevention of foetal complications. Both a gestational age of 34 weeks and serum bile acid levels of $34 \mu \mathrm{mol} / \mathrm{L}$ at the time of ICP diagnosis seem to be important independent factors to predict foetal complications in ICP patients.

\section{REFERENCES}

1. Williamson C, Geenes V. Intrahepatic cholestasis of pregnancy. Obstet Gynecol. 2014; 124(1): 120-133, doi: 10.1097/AOG.0000000000000346, indexed in Pubmed: 24901263

2. Herrera CA, ManuckTA, Stoddard GJ, et al. Perinatal outcomes associated with intrahepatic cholestasis of pregnancy. J Matern Fetal Neonatal Med. 2018; 31(14): 1913-1920, doi: 10.1080/14767058.2017.1332036, indexed in Pubmed: 28581354.
3. Perez MJ, Macias RIR, Marin JJG. Maternal cholestasis induces placental oxidative stress and apoptosis. Protective effect of ursodeoxycholic acid. Placenta. 2006; 27(1): 34-41, doi: 10.1016/j.placenta.2004.10.020, indexed in Pubmed: 16310035.

4. Geenes VL, Lim YH, Bowman N, et al. A placental phenotype for intrahepatic cholestasis of pregnancy. Placenta. 2011; 32(12): 1026-1032, doi: 10.1016/j.placenta.2011.09.006, indexed in Pubmed: 22015023.

5. Glantz A, Marschall HU, Mattsson LA. Intrahepatic cholestasis of pregnancy: Relationships between bile acid levels and fetal complication rates. Hepatology. 2004; 40(2): 467-474, doi: 10.1002/hep.20336, indexed in Pubmed: 15368452.

6. Geenes V, Williamson C. Intrahepatic cholestasis of pregnancy. World Journal of Gastroenterology. 2009; 15(17):2049, doi: 10.3748/wjg.15.2049.

7. Estiú MC, Frailuna MA, Otero C, et al. Relationship between early onset severe intrahepatic cholestasis of pregnancy and higher risk of meconium-stained fluid. PLoS One. 2017; 12(4): e0176504, doi: 10.1371/journal.pone.0176504, indexed in Pubmed: 28437442.

8. Wikström Shemer E, Marschall HU, Ludvigsson JF, et al. Intrahepatic cholestasis of pregnancy and associated adverse pregnancy and fetal outcomes: a 12-year population-based cohort study. BJOG. 2013; 120(6): 717-723, doi: 10.1111/1471-0528.12174, indexed in Pubmed: 23418899.

9. Martineau M, Raker C, Powrie R, et al. Intrahepatic cholestasis of pregnancy is associated with an increased risk of gestational diabetes. Eur J Obstet Gynecol Reprod Biol. 2014; 176: 80-85, doi: 10.1016/j.ejogrb.2013.12.037, indexed in Pubmed: 24462052.

10. Madazli R, Yuksel MA, Oncul M, et al. Pregnancy outcomes and prognostic factors in patients with intrahepatic cholestasis of pregnancy. J Obstet Gynaecol. 2015; 35(4): 358-361, doi: 10.3109/01443615.2014.968102, indexed in Pubmed: 25384180.

11. Geenes V, Chappell LC, Seed PT, et al. Association of severe intrahepatic cholestasis of pregnancy with adverse pregnancy outcomes: a prospective population-based case-control study. Hepatology. 2014; 59(4): 1482-1491, doi: 10.1002/hep.26617, indexed in Pubmed: 23857305.

12. Cui $D$, Zhong $Y$, Zhang $L$, et al. Bile acid levels and risk of adverse perinatal outcomes in intrahepatic cholestasis of pregnancy: A meta-analysis. J Obstet Gynaecol Res. 2017; 43(9): 1411-1420, doi: 10.1111/jog.13399, indexed in Pubmed: 28691322.

13. Kawakita T, Parikh LI, Ramsey PS, et al. Predictors of adverse neonatal outcomes in intrahepatic cholestasis of pregnancy. Am J Obstet Gynecol. 2015; 213(4): 570.e1-570.e8, doi: 10.1016/j.ajog.2015.06.021, indexed in Pubmed: 26071912.

14. Oztas E, Erkenekli K, Ozler $\mathrm{S}$, et al. Can routine laboratory parameters predict adverse pregnancy outcomes in intrahepatic cholestasis of pregnancy? J Perinat Med. 2015; 43(6): 667-674, doi: 10.1515/jpm-20140207, indexed in Pubmed: 25294714.

15. Rook M, Vargas J, Caughey A, et al. Fetal outcomes in pregnancies complicated by intrahepatic cholestasis of pregnancy in a Northern California cohort. PLoS One. 2012; 7(3): e28343, doi: 10.1371/journal. pone.0028343, indexed in Pubmed: 22403605.

16. Campos GA, Castillo RJ, Toro FG. [Effect of bile acids on the myometral contractility of the isolated pregnant uterus]. Rev Chil Obstet Ginecol. 1988; 53(4): 229-233, indexed in Pubmed: 3153079.

17. Germain AM, Kato S, Carvajal JA, et al. Bile acids increase response and expression of human myometrial oxytocin receptor. Am J Obstet Gynecol. 2003; 189(2): 577-582, indexed in Pubmed: 14520238.

18. WILLIAMSON C, GORELIK J, EATON B, et al. The bile acid taurocholate impairs rat cardiomyocyte function: a proposed mechanism for intrauterine fetal death in obstetric cholestasis. Clinical Science. 2001; 100(4): 363-369, doi: 10.1042/cs1000363.

19. Williamson C, Gorelik J, Eaton BM, et al.The bile acid taurocholate impairs rat cardiomyocyte function: a proposed mechanism for intra-uterine fetal death in obstetric cholestasis. Clin Sci (Lond). 2001; 100(4): 363-369, indexed in Pubmed: 11256973.

20. Miragoli M, Kadir SH, Sheppard MN, et al. A protective antiarrhythmic role of ursodeoxycholic acid in an in vitro rat model of the cholestatic fetal heart. Hepatology. 2011; 54(4): 1282-1292, doi: 10.1002/hep.24492, indexed in Pubmed: 21809354. 